\title{
Air Pollution, Allocation of Property Rights, Environmental Issues and Theoretical Overlapping Generations General Equilibrium Modelling
}

Jules Eric Tchouto*

Abstract:

This paper presents how the environment - considered as a production factor - and other related assumptions can be introduced step by step in a theoretical Overlapping Generations General Equilibrium Model (OLG - GE). The first part shows the behaviors of agents with pollution in the absence of an environmental policy. The second part emphasizes a Greenhouse Gas abatement policy through the allocation of Pollution Permit ownership, which allows property rights on the environment; here we assume a three-factor model: Capital - Labor Environment. The last part of of the paper highlights one theoretical property about the allocation of pollution permits within a OLG-GE steady state with the environment. To our knowledge, it is the first time that the aforementioned property has been characterized.

Keywords: Environment Property Right, Pollution Permit Ownership, Environmental Maintenance, Air Pollution, OLG-GE model, Intergenerational Equity.

JEL: D62, D91, Q50, C68

DOI: $10.2478 / v 10033-011-0003-1$

\section{Introduction}

Since the Kyoto agreement, quantitative constraints have been introduced with a Greenhouse Gas (GHG) abatement scheme using air pollution permits, which is a way to define property rights on the environment, following the Caose (1960) theorem. Otherwise, these property rights offer many opportunities in terms of analysis when the methodological framework mobilized is considered.

Compared with other instruments of environmental policies, the Pollution Permits System presents some main advantages, such as its simplicity and its use of incentives to achieve abatement at a minimal cost to society. In addition, as outlined by Jouvet et al. (2002), another advantage is that it operates ex-ante on the environment and allows emissions to be fixed, leaving prices to adjust. Otherwise, the Pollution Permits System gives wide flexibility in terms of adaptation to changes in

\section{* Jules Eric Tchouto \\ University of Rouen, France, \\ E-mail: juleric.tchouto@univ-rouen.fr}

the macroeconomic environment.

As international issues emerge in establishing a fund for the financing of climate change impacts (the Cancun UNCC Conference (2010)), this paper presents the particularity of highlihting these issues from the allocation of property rights within a relevant theoretical framework, the overlapping generations (OLG) model.

Indeed, in recent years, increasing attention has been dedicated to policies aimed at mitigating GHG emissions. Among this literature, many have focused mostly on the short term economic effects of the Pollution Permits System (Bergman (1991), Labandeira et al. (2004a), (2004b), Gonzalez et al. (2005), and Fullerton et al. (2007)). However, due to the long-term effects of GHG, as emphasized by Rasmussen (2003), environmental policies are considered within a very long timeframe, which naturally raises the question of intergenerational equity ${ }^{1}$;

\footnotetext{
${ }^{1}$ Weak and strong sustainability are two different ways of looking at the need to ensure that future generations can supply their needs. See Weiss (1990) or Beder (1996) for more details.
} 
this is the concept that current generations hold the environment as natural capital in common with future generations. Therefore, present generations need not reduce the ability of future ones to meet heir needs. Hence, we introduce in this paper a mechanism which shows that young generations will be in charge of selling pollution permits to firms.

As outlined by Schelling (1995) using the Infinite Life Agent (ILA) model with environmental problems involves a fallacy of composition in intergenerational fairness. Therefore, abatement policies should be seen in the context of decisions involving intergenerational redistribution. Moreover, as underlined by Gerlagh et al. (2000), although a dynastic framework might be convenient for economic analysis, it is restrictive and can be misleading. On the other hand, OLG models are more flexible and may give results different from those derived from dynastic models.

In order to capture the long-term macroeconomic impacts of implementing TEP into an economy, OLG models seem to be more appropriate. The use of this aforementioned framework initially developped by Diamond (1965) is spreading in the literature, especially in environmental economics (John et al. (1994), Ono (1996), Stockey (1998), Grimaud (1999), Gerlagh et al. (2001), Ono (2002), Jouvet et al. (2002), Lambrecht (2005), Jouvet et al. (2006)).

In Jouvet et al. (2006) pollution is regulated by a system of tradable emission permits under political constraints. Jouvet et al. (2002) consider the question of the tradable emission permits variations' effects on longterm capital accumulation. Ono (1996) and John et al. (1994) implement environmental policies by applying financial controls on polluting activities. Ono (2002), Grimaud (1999) and Stockey (1998) introduce pollution permits in order to obtain an optimum allocation of capital and environmental protection. However they do not consider the effects in the variation in the number of permits, or on environmental quality. Gerlagh et al. (2000) show through an Integrated Assessment Model mainly that GHG abatement efficiency could be indirectly influenced by institutional decisions (interest rate) set to face a demographic change scenario. A rule of initial allocation of property rights (grandfathering) is designed for environmental protection. Lambrecht (2005), like Ono (2002), believes that the initial allocation of tradable emission permits would be through sales to companies. Lambrecht (2005) shows how the introduction of a permit system could generate capital accumulation compared to a 'laissez-faire' equilibrium. Both previous authors offer an environmental protection policy based on investment in the operation of environmental maintenance financed by young generations.

Following Beltrati (1996) and Jouvet et al. (2002) we assume that Pollution Permits can be used as investments or financial assets which need to be financed to achieve an equilibrium. We also assume that when an environmental policy is set by the Public Authority, property rights are defined on the environment and ownership is given to young generations, yet within our ideas of green fiscal policy and the use of this levy-fund.

Whilst our approach is closer to these papers from Lambrecht (2005), Ono (2002), Jouvet et al. (2002), Jouvet et al. (2006), nevertheless we differ by coupling a green fiscal system and Pollution Permits. The source of financing in terms of our taxation system is different from those of previous authors. In our approach, as did these previous authors, we deal with the question of environmental maintenance.

However, we differ from them on one hand by treating the investment/financial asset (tradable emission permits) as a source of income; this justifies the implementation of our fiscal policy on this income. On the other hand, we depart from the use of this fund (finance environmental debt and adaptation funding, equity - solidarity and intergenerational issues). Even though we assume GHG reduction policy aims as in Gerlagh et al. (2000) with allocation of property rights in our approach, property rights through Pollution Permits are not initially assigned for free to young generations and we do not regard ageing aspects. As a result, we do not consider the grandfathering allocation rule in this paper.

This paper is organized as follows. The Business as Usual frame is presented in section 2. The environment quality modelling here shows that to reduce GHG emissions, environmental policies are necessary. The two following sections characterize the OLG model with green policies with intertemporal capital equilibrium, and the study of theoretical property and implication of TEP allocation is defined here; to our knowledge, the concept of allowing property rights on the environment coupled with a green fiscal policy has not yet been broached within the framework of overlapping generations models. The last section concludes the paper. 


\section{Characteristics of the Model}

\subsection{Business as Usual Economy BAU}

We assume an overlapping generations model (OLG) as in Diamond's (1965) model. Production activities generate negative environmental externality under "laissez-faire" conditions because of the absence of environmental policy.

\subsubsection{Household Behavior}

A representative agent lives over a two-period ${ }^{2}$ live span (young and old) $\left(\mathrm{H}_{1}\right)^{3}$. He offers an inelastic unit of work, and receives in return a wage $w_{t}$. He uses his income for domestic consumption $-c_{t}$, and savings $s_{t}$ $\left(H_{2}\right)$. During retirement, he consumes $b_{t+1}$ (See [1] below) which is the net return on the savings during the activity period, and receives from the government his pension $\left(T R F_{t+1}\right)\left(\mathrm{H}_{3}\right)$. A fiscal policy is implemented on all the incomes (capital, wage, and pension) $\left(\mathrm{H}_{4}\right)$ to finance the government budget and expenditures $\left(\lambda_{t}\right)$.

In this first part of the model, we assume that the variables and parameters used are doubly indexed: on the one hand in time $(t)$, and on the other hand, the economic situation ('BAU) ${ }^{4}$.

Household maximization program:

2 Cf. Model of Diamond [1958], p.449, in Truman F. Bewley 2007 General Equilibrium, Overlapping Generations Models and Optimal Growth Theory, Harvard University Press, Cambridge or Schubert (2000), pp. 270-285.

${ }^{3}(\mathrm{Hi})$ for hypothesis $i$.

${ }^{4}$ To simplify the writing of the equations, $\forall x$, variable index in $\mathrm{t}$, or $\forall \varepsilon$ parameter of the model indexed in $\mathrm{t}$ considered as in this first part of the model $x_{t}^{B A U}$ and $\varepsilon_{t}^{B A U}$, for parameters not indexed in t, consider as $\varepsilon^{B A U}$.
$[1] \quad\left\{\begin{array}{l}\underset{c_{t}, c_{t+1}}{\operatorname{Max}}\left\{U\left(c_{t}, c_{t+1}\right)\right\} \\ c_{t}+s_{t}=w_{t}\left(1-\lambda_{t}\right)\left(1-\operatorname{Tau}_{t}\right) \\ b_{t+1}=\left[1+r_{t+1}\left(1-\lambda_{t+1}\right)\right] s_{t}+T R F_{t+1}\left(1-\lambda_{t+1}\right)\end{array}\right.$

\subsubsection{Intertemporal Optimization}

The optimization problem under constraints within the OLG framework is resolved through the construction of the Intertemporal Budgetary Constraints (IBC) relation. In this first part we have specified a logarithmic utility function.

$$
U\left(c_{t}, b_{t+1}, \psi\right)=\log \left(\psi c_{t}\right)+\varphi \log \left(\psi b_{t+1}\right)
$$

Where $\psi \in(0,1)$ represents an index of environmental quality; $\varphi$ is the time preference rate.

The closer this index approaches its maximum value, the better the environmental quality will be, and consumption will not be affected. Inversely, as we move away from this maximum value due to harmfulness, the negative impact on the agent's utility for each period of life will be greater.

The aforementioned IBC is:

$$
c_{t}+\frac{b_{t+1}}{\left[1+r_{t+1}\left(1-\lambda_{t+1}\right)\right]}=w_{t}\left(1-\lambda_{t}\right)\left(1-\operatorname{Tau}_{t}\right)+\frac{T R F_{t+1}\left(1-\lambda_{t+1}\right)}{\left[1+r_{t+1}\left(1-\lambda_{t+1}\right)\right]}
$$

Where:

- $T R F_{t+1}$ : Transfer or Pension received from government revenue in the second part of the life cycle (retirement) ;

- $T R F_{t}=\operatorname{Tau}_{t} \cdot w_{t}$.

- $r_{t+1}$ : Interest rate between the period $t$ and $t+1$, on the capital market ;

\subsubsection{Optimal Consumption}

Writing the following expression as being the 'Discounted Life Cycle Income' (named RCV): 
[4] $R i C V i_{t}=w_{t}\left(1-\lambda_{t}\right)\left(1-\operatorname{Tau}_{t}\right)+\frac{T R F_{t+1}\left(1-\lambda_{t+1}\right)}{\left[1+r_{t+1}\left(1-\lambda_{t+1}\right)\right]}$

Optimal consumption in the first and second periods (Intertemporal consumption) is established as:

$$
c_{t}^{B A U}=\operatorname{RiCVi}\left(\frac{1}{1+\varphi}\right)
$$

$$
b_{t+1}^{B A U}=\varphi \cdot c_{t}^{B A U} \cdot\left[1+r_{t+1}\left(1-\lambda_{t+1}\right)\right]
$$

Relation [6] is the well-known 'Euler's Intertemporal Equation ${ }^{5}$ which is expressed in terms of the first period of optimal consumption. This equation stated the hypothesis that there is a no-inheritance assumption, as all the cumulated savings during the first period are used. Applying $N_{t}=N_{t-1}$ and that the aggregate consumption $^{6}\left(C_{t}^{B A U}=N_{t} c_{t}^{t}+N_{t-1} b_{t}^{t-1}\right)$ during a given period $t$ is the sum of both generations at each current period, we have:

$$
C_{t}^{B A U}=N_{t} \operatorname{RiCVi}_{t}\left(\frac{1}{1+\varphi}\right)+N_{t}\left(\frac{\varphi}{1+\varphi}\right) \operatorname{RiCVi}_{t}\left[1+r_{t+1}\left(1-\lambda_{t+1}\right)\right]
$$

Thus:

$$
C_{t}^{B A U}=\frac{N_{t} R i C V i_{t}}{(1+\varphi)}\left(1+\varphi\left[1+r_{t+1}\left(1-\lambda_{t+1}\right)\right]\right)
$$

\subsection{Firms}

\subsubsection{Production}

Production $\left(Y_{t}\right)$ of an aggregated good is done by a firm with a Cobb-Douglas function.

$$
Y_{t}^{B A U}=A K_{t}^{\alpha} L_{t}^{1-\alpha} \varsigma_{t}
$$

Where $A>0$ is a parameter of scale, and $K_{t}>0$, $L_{t}>0$ are respectively the capital and labor employed

${ }^{5}$ Cf. Obstfeld, M., Kenneth, R. [1997], Foundations of international macroeconomics, The MIT Press, 2ème edition, Cambridge.

${ }^{6}$ The aggregate consumption is called $C_{t}^{B A U}$. during the period $\mathrm{t}$, and $0<\alpha<1$. The intensity of the pollution is defined by $\varsigma_{t} \in(0,1)$.

This production generates a quantity of emission $\left(E m_{t}\right)$ at each period ${ }^{7}$ as the following expression:

$$
E m_{\mathrm{t}}=\varsigma_{t}^{1 / \theta} Y_{t}
$$

The expressions [9] and [10] allow a more general expression of the intensity of the pollution emitted during a given period $\mathrm{t}$ :

$$
\varsigma_{t}=\left(\frac{E m_{t}}{A K_{t}^{\alpha} L_{t}^{1-\alpha}}\right)^{\frac{\theta}{1+\theta}}
$$

As there is no environmental policy, pollution intensity is at its maximum value: $\left(\varsigma_{t}=1\right)$. Therefore:

$$
E m_{t}=Y_{t}^{B A U} \quad \text { with } \quad Y_{t}^{B A U}=A K_{t}^{\alpha} L_{t}^{1-\alpha}
$$

Assuming perfect competition, and each firm's choices in capital and labor to maximize profits with $\left(k_{t}^{\alpha}=K_{t}^{\alpha} / L_{t}^{\alpha}\right)$, the capital per head:

$$
\pi_{t}=A k_{t}^{\alpha}-\left(w_{t} L_{t}+\left(r_{t}+\delta\right) K_{t}\right)
$$

This is achieved by equalizing the marginal productivity of the factors employed in the production process at their real cost. The capital is not entirely depreciated and we assume no adjustment cost of capital.

\subsubsection{Relative Prices}

Given decision variables $K_{t}, L_{t}$ :

$$
\left\{\operatorname { M a x } _ { K _ { t } , L _ { t } } \{ \pi _ { t } ^ { B A U } \} \quad \text { et } \left\{\begin{array}{l}
\frac{\partial \pi_{t}^{B A U}}{\partial X_{i}}=0 \\
X_{i, t}=K, L
\end{array}\right.\right.
$$

With :

\footnotetext{
${ }^{7}$ Even though consumption is at the origin of pollution, we assume here that emissions are linked only to production.
} 
- $\alpha$ : the rate of capital in production;

- $\delta$ : Capital depreciation rate

- $\pi_{t}$ :Firm profits.

From the optimality conditions, we obtain the relative prices:

\subsubsection{Investment}

Capital accumulation is characterized by this relation:

$$
I_{t}=K_{t+1}-(1-\delta) K_{t} \quad[14 b i s]
$$

\subsection{Government}

\subsubsection{Budget and Public Expenditures}

Public expenditures and retirement income are funded by taxes applied on all the revenues at rate $\left(\lambda_{t}\right)$.

During the present period $t$, the equation of public expenditure $\left(G P_{t}\right)$ is hence:

$$
G P_{t}^{B A U}=\lambda_{t} N\left[w_{t}\left(1-\operatorname{Tau}_{t}\right)+r_{t} s_{t-1}+T R F_{t}\right]
$$

The Public Authority budget is used to finance public goods and pension plans.

\subsubsection{Retirement Funds Held by the State}

The retirement budget used to finance transfers to the older generation comes from taxes on the young generation's gross wage.

[4] $T R F_{t}^{B A U} N_{t-1}=\operatorname{Tau}_{t} w_{t} L_{t} \Rightarrow>\operatorname{TRF} F_{t}^{B A U} N_{t}=\operatorname{Tau}_{t} w_{t} L_{t} \Rightarrow>\operatorname{TRF} F_{t}^{B A U} N_{t}=\operatorname{Tau}_{t} w_{t} N_{t}$

\subsection{The Quality of the Environment}

We assume that production is at the origin of the pollution concentration in the atmosphere. At each moment, this concentration $\left(H_{t}>0\right)$ for all of the GHG as shown below is:

$$
H_{t}=(1-\vartheta) H_{t-1}+\phi\left(c_{t-1}^{t-2}+c_{t-1}^{t-1}\right)+\mu E m_{t-1}
$$

Where $\vartheta$ is the rate of natural absorption of the atmosphere and $\phi$ is a control parameter of household consumption externality. Being given the variable of the level of environmental quality $E Q_{t}$ in the absence of maintenance operations given a reference value of environmental quality $E Q_{\text {ref }}$ of $\mathrm{GHG}$ in the atmosphere even without human activity, we may write the following relation for all periods:

$$
E Q_{t}=E Q_{r e f}-H_{t}
$$

From the relations below, the level of environmental quality at each period $t$ is:

[7]

$$
E Q_{t}=E Q_{t-1}+\vartheta\left(E Q_{r e f}-E Q_{t-1}\right)-\phi \psi\left(c_{t-1}^{t-2}+c_{t-1}^{t-1}\right)-\mu E m_{t-1}
$$

\subsubsection{In Any Steady State}

In the presence of GHG, we obtain the steady state environment quality, from [5] and [6]:

$$
E Q^{s}=E Q_{r e f}-\frac{\mu}{\vartheta} E m-\frac{\varphi \phi}{\vartheta} \operatorname{RiCVi}\left(\frac{1}{1+\varphi}\right)\langle 1+\vartheta\{1+r(1-\lambda)\}\rangle
$$

From this equation [23]; we establish the following conclusions:

\section{Proposition 1}

In the absence of any environmental policy and considering everything else to be otherwise equal, the stationary quality of the environment as modelled here is a positive function of the natural concentration of GHG present in the atmosphere without production activity or consumption; and a negative function of the quantity of pollution emitted; the discount life cycle income and key economic parameters. ${ }^{8}$

The observation in this proposition leads to the fact that it could be necessary for the Public Authority to

\footnotetext{
${ }^{8}$ Actual policy for interest rates and levels of taxes introduced and applied on the households' income.
} 
contemplate environmental policies in order to set down GHG abatement policies.

\subsubsection{Defining the BAU Equilibrium}

An equilibrium is defined by $\left\{E Q_{t}, k_{t}, c_{t}, s_{t}, w_{t}, r_{t}, G P_{t}\right\}_{t=0}^{\infty}$ so that households taking into account the initial conditions $\left(s_{-1}=k_{0}, E Q_{0}=E Q_{r e f}\right)$ to maximize their intertemporal utility, under the defined constraints, firms maximize their profits and market hold (capital $S_{t}=K_{t+1}$, Labour $L_{t}=N_{t}$, and goods

$$
\left.Y_{t}=C_{t}+I_{t}+G P_{t}\right)
$$

\section{Overlapping Generations Model with Environmental Policy ${ }^{9}$}

\subsection{Overview}

As mentioned above, GHG emissions come from firms' production activities, and decrease households' welfare. These GHG are also harmful to environmental quality through their negative impacts. The environment is considered a public good. We assume in this second part that firms have the same technology, and that the fossil fuel used in the production process is the main source of GHG.

\subsection{Instrument of Environmental Policy}

The Public Authority is a member of a Supranational Committee ${ }^{10}$ and has decided on the adoption of binding agreements through quantitative emissions targets. Therefore, a tradable emission permits system is implemented in the economy as an international mobilization $\left(\mathrm{H}_{5}\right)$.

\footnotetext{
9 The variables and parameters of this $2^{\text {nd }}$ part are assumed to be indexed on $x_{t}^{W E}, \varepsilon_{t}^{W E}, \varepsilon^{W E}, \forall x_{t}, \varepsilon_{t}, \varepsilon$ where WE means With Environment.

${ }^{10}$ As in the European Union, for example.
}

\subsubsection{Initial Allocation of Pollution Permits}

Here, property rights are defined in terms of the environment. Indeed, under temporal flexibility, we assume that these private rights are owned and purchased from the Public Authority at price $p_{t}$ only by young households; these property rights are resold at a profit on a tradable emission permits market $\left(\mathrm{H}_{6}\right)$ to firms which cannot use the flexibility of the system; this means that they are unable to invest in clean-production technology and reduce their GHG emissions as depicted in graph 1 , below. Moreover, at each period, the property rights generate an amount of income $\left(p_{t} \bar{E}\right)$.

These assumptions are quite close to John et al. (1994), John et al. (1995), and Ono (2002) within the framework of an overlapping generations model in the case of environmental externalities. In their approach, they assume the existence of a Public Authority which represents young households and operates an environmental maintenance policy to their advantage. The amount of property rights at the beginning of the period is equal to exogenous emission targets $\left(\mathrm{H}_{7}\right)$ initially set by the Supranational Committee during agreement negotiations.

\subsubsection{Further Assumptions and Propositions}

$\mathrm{H}_{8}$

As $q_{t}$ is the resell price of emission permits to firms, we assume $\left(q_{t}>p_{t}\right)$ so $\frac{q_{t}}{p_{t}}>1$. Given this, a green fiscal policy at $\operatorname{rate}\left(\xi_{t} \in\right] 0,1[)$ can be introduced and implemented on the gross revenue 'added' value $\left(d_{t}=\left(q_{t}-p_{t}\right) E_{t}\right)$ coming from these property rights.

$\mathrm{H}_{9}$

i. The total value of the property rights $\left(p_{t} \bar{E}\right)$ and the funds made up from the $\operatorname{tax}\left(\xi d_{t} E_{t}\right)$, feeds the budget $G P_{t}^{W E}$ of the Public Authority which could be allocated to operating environmental maintenance. 


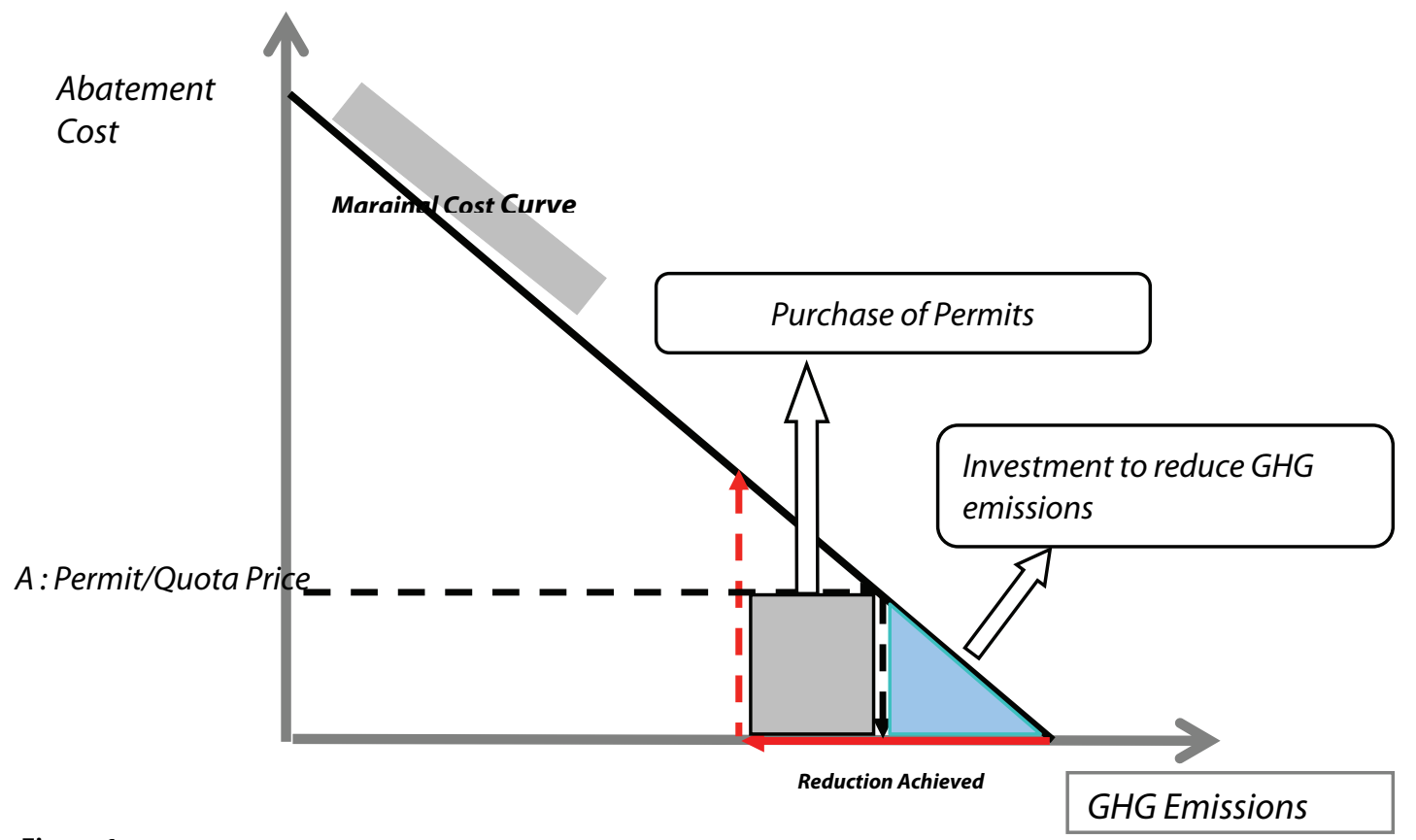

Figure 1

ii. Tax fund and property rights income could be used for achieving two policies:

1. In the absence of further administrative costs the budget surplus could be used for national environmental maintenance operations like :

a. reforestation for carbon sinks to enhance natural and artificial carbon sequestration reforestation;

b. Investment in renewable energy sources like wind farm parks for street lighting.

\section{Proposition 2}

Operations in the frame of national environmental maintenance could generate positive welfare effects and involve the development of sustainable energy not harmful to the environment. We qualify these impacts here as 'greenintergenerational positive welfare effects.'

2. Furthermore, the fund from the tax collected could feed the Common Supranational Committee fund for international solidarity actions like humanitarian aid in case of natural disasters occurring because of global warming, climate change or the effects of air pollution.

\section{Proposition 3}

Participating in international humanitarian operations mainly in developing countries is therefore an equity decision. Indeed, by considering the debate about 'ecological debt,' taking into account this reality concerning historical air pollutions ascribable to industrial or Northern countries (older generations), Southern countries which mainly suffer from natural climate change disasters need to be compensated. In this view, this operation could also consist of financing adaptations for mitigation purposes in those disadvantages areas.

\section{Proposition 4}

A future expectation with regard to current generations taking part in measures of international solidarity would also serve to avoid the accumulation of the aforementioned debt.

iii. If $\frac{q_{t}}{p_{t}} \equiv 1, \frac{q_{t}}{p_{t}} \equiv 1, \operatorname{tax}$ amount is (almost) null $\left(\xi_{t} d_{t} e_{t} \equiv 0\right)$, and the Public Authority in this case cannot levy sufficient taxes and does not realize any environmental maintenance or adaptation activities. If the Public Authority wishes to maintain its participation in these operations, this decision will create an excess of expenditures. Consequently it has the choice between creating a deficit to be covered by future generations (creating intergenerational 
inequity) or not investing in environmental maintenance or other related activities.

\subsection{Firm Behavior and GHG Emissions}

\subsubsection{The Three-factor Production Function}

Firms rent the Environment-Factor to households assuring production of an aggregate good in each period. The so-called neoclassical production technology with constant returns to scale is also considered. However, three factors are used in this second part: Physical capital $\left(K_{t}\right)$, Labor $\left(L_{t}\right)$ and the Environment $(E)$ (Emission permits represent the demands of the Environment Factor) $\left(\mathrm{H}_{8}\right)$. The use of tradable permits in the production process can be helpful to set a control on GHG emissions, and to reduce firms' clean technological adaptation costs through the real demand of permits.

For each period the production function is represented by:

[9]

$F\left(K_{t}, L_{t}, E_{t}\right)=Y_{t}^{W E}=A K_{t}^{\alpha_{K}} L_{t}^{\alpha_{L}} E_{t}^{\alpha_{E}} \quad$ With $\sum \alpha_{i}=1 \quad(i=K, L, E)$

This equation may also be written as:

[10] $Y_{t}^{W E}=A K_{t}^{\alpha} L_{t}^{\beta} E_{t}^{1-\alpha-\beta} \quad$ with $\alpha+\beta+\gamma=1$ où $\gamma=1-\alpha-\beta$

The problem of the representative firm consists in maximizing its new profit function below:

$$
\pi_{t}^{W E}=A K_{t}^{\alpha} L_{t}^{\beta} E_{t}^{1-\alpha-\beta}-\left\{w_{t} L_{t}+\left(r_{t}+\delta\right) K_{t}+q_{t} E_{t}\right\}
$$

$$
\frac{\partial \pi_{t}}{\partial x_{i}}=0 \text { where } x_{i}=\left(K_{t}, L_{t}, E_{t}\right)
$$

\subsubsection{New Relative Prices}

From this equation[13], the relative prices are:

$$
\begin{array}{r}
r_{t}^{w e}=\alpha A k_{t}^{\alpha-1} e_{t}^{\gamma}-\delta^{w e}=F_{K}\left(k_{t}, e_{t}\right) \\
w_{t}^{w e}=\beta A k_{t}^{\alpha} e_{t}^{\gamma}=F_{L}\left(k_{t}, e_{t}\right) \\
q_{t}^{w e}=\gamma k_{t}^{\alpha} e_{t}^{\gamma-1}=F_{E}\left(k_{t}, e_{t}\right)
\end{array}
$$

Where $r_{t}^{w e}, w_{t}^{w e}, q_{t}^{w e}$ are respectively the new interest rate, wages and the unit price of tradable emission permits and $e_{t}=E_{t} / L_{t}$ represents the emissions per head.

\subsubsection{Investment Equation}

Capital accumulation is the same as seen in equation [17]

$$
I_{t}=K_{t+1}^{\alpha}-(1-\delta) K_{t}
$$

\subsubsection{Dynamics of GHG Emissions and Pollution Accumulation Taken into Account}

At each period $t$ firms in a competitive market are allowed to emit as much pollution as they have has acquired the rights to emit, or by owning it on the tradable emissions market where households are sellers. Pollution is generated by the use of emissions permits in the firms' activities, and has negative impacts on environmental quality. Hence there is a negative correlation between Pollution Permits and the quality of the environment. As found in Jouvet et al. (2002), 'pollution stock at a particular time $t$ depends on the stock of pollution of the preceding period - and of the demand of tradable emission permits revealed by firms during the current period.'

Taking $\vartheta$ as the natural level of pollution absorption, we can assume that the total level of pollution follows this dynamic:

$$
H_{t+1}=(1-\vartheta) H_{t}+\phi \psi N_{t}\left(c_{t}^{t}+\Gamma c_{t}^{t-1}\right)+\mu E_{t}
$$

Where $\Gamma \in(0,1)$ is the probability that an individual dies before the end of the second period of his life under the harmful effects of GHG, such as scorching heat. What is more, on a national plan, growing statistics about this heat wave and mortality rate among the old generation could urge the Public Authority to react, and invest in environmental maintenance. 
3.4. Behavior of Other Institutional Components of the Model

\subsubsection{Households}

The general characteristics concerning the life cycle of the agents remain identical as above. The representative consumer in a cohort maximizes his/her preferences which are expressed across the inter-temporal utility function below. This is written with a separable consumption function over the two periods and within a parameter $\vartheta \in(0,1)$, an environmental quality index which affects life cycle consumption. It also reflects the sensitiveness of consumers to the conditions in which they consume. The household program is:

\section{Optimization Program:}

$$
\underset{\substack{\text { Me } \\ c_{t}^{w e}, b_{t+1}^{w e}}}{\operatorname{wax}}\left\{U\left(c_{t}^{w e}, b_{t+1}^{w e}, \vartheta\right)\right\} \text { ò̀ } \vartheta=f\left(E Q_{i}\right) \quad \forall i \in\{t\}
$$

$$
w_{t}^{w e}\left(1-\lambda_{t}^{w e}\right)\left(1-\operatorname{Tau}_{t}^{w e}\right)+\left[q_{t}\left(1-\xi_{t}\right)-p_{t}\right] E_{t}=c_{t}^{w e}+s_{t}^{w e}
$$

[35] $\left[1+r_{t+1}^{w e}\left(1-\lambda_{t+1}^{w e}\right)\right] s_{t}^{w e}+T R F_{t}^{w e}\left(1-\lambda_{t+1}^{w e}\right)=b_{t+1}^{w e}$

Equations [34],[35] are the budget constraints which take into account the initial allocation of permits.

\section{Proposition 5}

The introduction of tradable emission permits in the economy, the definition of property rights on the environment and their introduction in households' budget constraints change the allocation of household income.

Indeed, here young households' incomes are used for consumption $c_{t}$, saving as well as for owning property rights on the environment $p e_{t}$ from the Public Authority. In fact, their income is increased by the net amount $q_{t}^{w e}\left(1-\xi_{t}\right) E_{t}$.
In their retirement, old agents' consumption $b_{t+1}$ is financed with the net returns from savings during their period of activity, and the net transfer received from the government pension plan.

Taking into account the fact that tradable emission permits are a financial asset, and under the temporal flexibility assumption, our initial allocation scheme will favor saving if consumption in the presence of the environmental policy remains equivalent to the consumption in BAU situations, all other things being equal. The following expression is the young savings function in this framework.

$$
s_{t}^{w e}=w_{t}^{w e}\left(1-\lambda_{t}^{w e}\right)\left(1-\operatorname{Tau}_{t}^{w e}\right)+\left[q_{t}\left(1-\xi_{t}\right)-p_{t}\right] E_{t}-c_{t}^{w e}
$$

During their retirement period, old agents consume $b_{t+1}^{w e}$ which corresponds to the net return on the new expression of savings $s_{t}^{\text {we }}$ realized during the active period, and to the net amount of transfers given by the Public Authority in its pension plan.

The following function given below allows us to estimate households' utility:

$$
U\left(c_{t}^{w e}, b_{t+1}^{w e}, \vartheta\right)=U\left(c_{t}^{w e}, \vartheta\right)+\left(\frac{1}{1+\varphi}\right) U\left(b_{t+1}^{w e}\right)
$$

$$
\begin{aligned}
& U\left(c_{t}^{w e}, \vartheta\right)=\left(\frac{1}{1-\frac{1}{\sigma}}\right) \vartheta\left(c_{t}^{w e}\right)^{1-\frac{1}{\sigma}} \text { and } \\
& U\left(c_{t}^{w e}, \vartheta\right)=\left(\frac{1}{1-\frac{1}{\sigma}}\right)\left(b_{t+1}^{w e}\right)^{1-\frac{1}{\sigma}}
\end{aligned}
$$

Where:

- $\sigma \neq 1$ is the elasticity of the inter-temporal substitution;

- $\varphi$ is the time preference rate $(\varphi \in[0,1])$. 


\subsubsection{Optimal Consumption}

With the constraints [34, [35], the maximization program is expressed as:

$$
\left\{\begin{array}{l}
\partial U\left(c_{t}^{w e}, b_{t+1}^{w e}\right) \\
s / c \\
{[34] \text { et [35] }}
\end{array}\right.
$$

$$
c_{t+1}^{w e}=\left\langle\frac{\operatorname{RiCVi}_{t}^{w e}\left\{\frac{\left[1+r_{t+1}^{w e}\left(1-\lambda_{t+1}^{w e}\right)\right]}{\vartheta(1+\varphi)}\right\}}{1+\left\{\frac{\left[1+r_{t+1}^{w e}\left(1-\lambda_{t+1}^{w e}\right)\right]^{\sigma-1}}{[(\vartheta)(1+\varphi)]^{\sigma}}\right\}}\right\rangle
$$

Where the Discounted Life Cycle Income $\left(R i C V i_{t}^{w e}\right)$ :

This leads to the optimal choice of consumption (marginal rate of substitution between consumption in the first and second periods) over the life cycle of an individual:

$$
\frac{U_{c}}{U_{b}}=\left\{\frac{1+r_{t+1}\left(1-\lambda_{t+1}\right)}{\vartheta(1+\varphi)}\right\}
$$

Consequently, consumption during the first and second periods is:

[40]

$$
c_{t}^{w e}=\operatorname{RiCV}_{t}^{w e}\left\langle 1-\frac{\left\{\frac{\left[1+r_{t+1}^{w e}\left(1-\lambda_{t+1}^{w e}\right)\right]^{\sigma-1}}{[(\vartheta)(1+\varphi)]^{\sigma}}\right\}}{1+\left\{\frac{\left[1+r_{t+1}^{w e}\left(1-\lambda_{t+1}^{w e}\right)\right]^{\sigma-1}}{[(\vartheta)(1+\varphi)]^{\sigma}}\right\}}\right\rangle
$$

After several manipulations equation [38] above gives:

$$
\operatorname{RiCVii_{t}^{we}}=w_{t}^{w e}\left(1-\lambda_{t}^{w e}\right)\left(1-T a u_{t}\right)+\left[q\left(1-\xi_{t}\right)-p_{t}\right] E_{t}+\frac{T R F_{t+1}^{w e}\left(1-\lambda_{t+1}^{w e}\right)}{1+r_{t+1}^{w e}\left(1-\lambda_{t+1}\right)}
$$

\subsubsection{Optimal Agregate Consumption and \\ Government Budget}

$$
C_{t}^{\text {we }}=N_{t} c_{t}^{\text {we }}+N_{t-1} b_{t}^{\text {wet }-1} ; \text { Or }, N_{t}=N_{t}^{t-1} ;==>C_{t}^{\text {we }}=N_{t}\left(c_{t}^{\text {we }}+b_{t}^{t-1}\right)
$$

\section{a. New Government Budget}

With the assumption of green taxes financing environmental maintenance and/or an international solidarity fund, as well as the avoidance of ecological debt, the budget of the Public Authority becomes:

$$
G P_{t}^{w e}=\lambda_{t}^{w e}\left[w_{t}^{w e}\left(1-T a u_{t}^{w e}\right)+r_{t}^{w e} s_{t-1}^{w e}+T R F_{t}^{w e}\right]+N_{t} E_{t}\left(p_{t}+\xi_{t} d_{t}\right)
$$

\subsection{Environmental Maintenance}

Public Authority environmental policies set during each period have a direct effect on the parameter $\vartheta \in(0,1)$, which increases or decreases the utility of agents, as the maintenance improves the quality of the environment. When this maintenance is realized at an optimal level, due to cumulative positive effects, environmental quality is better than during the current and next period $t+1$.

Assuming a constant level of emissions, the quality of the environment during period $t+1$ ii is bequeathed to the following generation, hence the positive intergenerational effect is emphasized. Therefore, logically, future young generations who will enter in the 
model will be consuming and living in a better environment.

\section{Proposition 5}

If the emission quota which is equal to the level of property rights, and GHG emissions assigned by the Supranational Committee are enforced, such that all the optimum relations presented above hold, the tax rate for achieving these policies will be the optimal one.

\subsection{Dynamics of Capital Accumulation in the OLG model with an Environment and Market Equilibrium} Summary

\subsubsection{Capital Accumulation}

As in Diamond's model, the total savings of the young generation are their savings $S_{1}$ in the economy and will be the stock of capital of the period $t+1$. So:

$$
S_{t}^{w e}=s_{t}^{w e} N_{t}=K_{t+1}
$$

With

$w_{t}^{w e}\left(1-\lambda_{t}^{w e}\right)\left(1-\operatorname{Tau}_{t}^{w e}\right)+\left[q_{t}\left(1-\xi_{t}\right)-p_{t}\right] E_{t}=\operatorname{RiCV}_{t}-\frac{T R F_{t+1}^{w e}\left(1-\lambda_{t+1}^{w e}\right)}{1+r_{t+1}^{w e}\left(1-\lambda_{t+1}\right)}$

The savings of the agents living and working in each period $t$ is:

$$
s_{t}^{w e}=\left\langle\operatorname{RiCV} i_{t}^{w e}\left\{\frac{\left\{\frac{\left[1+r_{t+1}^{w e}\left(1-\lambda_{t+1}\right)\right]^{\sigma-1}}{[\vartheta(1-\varphi)]^{\sigma}}\right\}}{1+\left\{\frac{\left[1+r_{t+1}^{w e}\left(1-\lambda_{t+1}\right)\right]^{\sigma-1}}{[\vartheta(1-\varphi)]^{\sigma}}\right\}}\right\}-\frac{T R F_{t+1}^{w e}\left(1-\lambda_{t+1}^{w e}\right)}{1+r_{t+1}^{w e}\left(1-\lambda_{t+1}\right)}\right\rangle
$$

One can note that this expression increases with Discounted Life Cycle Income $\left(\mathrm{RiCVi}_{t}\right)$ and a nondecreasing interest rate.

\subsubsection{Markets Equilibrium Summary}

The general equilibrium of the different markets is thus determined as follows:

\section{a. Labor Market}

The active population is equal to the number of young members in a cohort at each period $t$. So:

$$
N_{t}=L_{t}
$$

\section{b. Pollution Permits Market}

The quantity of permits on offer, on the basis of attributed charges, is equal to the number of permits required by the companies:

$$
\bar{E}=E_{t}
$$

\section{c. Market of Goods and Services}

As we are in a closed economy, the supply and the demand equilibrium on this market is verified when:

$$
Y_{t}^{w e}=C_{t}^{w e}+I_{t}^{w e}+G P_{t}^{w e}
$$

\section{d. Capital Market}

Walras's law asserts that when considering any particular market, if all other markets in an economy are in equilibrium, then that specific market must also be in equilibrium. As a consequence, this principle leads us to consider that equilibrium is achieved on the capital market.

Furthermore, we assume as in Schubert (2000) that at the initial period of the economy or in the one preceding the current period t, there were pre-existing savings $S_{-1}$ which financed the initial stock of capital $\left(K_{0}\right)$. Following this, the savings of the young generation will finance the stock of capital for investment in the economy, so that at each period $t$ we can have the equilibrium relationships $S_{t}^{w e}=s_{t}^{w e} N_{t}=K_{t+1}[44]$.

\subsection{Intertemporal Capital Equilibrium}

In this section the growth path is characterized within the environmental policy instrument.

From equation [44]: $S_{t}^{w e}=s_{t}^{w e} N_{t}=K_{t+1}$;

Taking the expressions of variables per head, and as it is assumed that generation sizes are constant, we obtain: 
Such that :

[50]

$$
s_{t}^{w e}=k_{t+1}
$$

Therefore, if:

$$
\left\{\frac{\left[1+r_{t+1}^{w e}\left(1-\lambda_{t+1}\right)\right]^{\sigma-1}}{[\vartheta(1-\varphi)]^{\sigma}}\right\}=\Upsilon_{t}^{w e}
$$

$$
k_{t^{*+1}}^{w e}=\left\{\operatorname{RiCVi}_{t}\left(\frac{\Upsilon_{t}^{w e}}{1-\Upsilon_{t}^{w e}}\right)-\frac{T R F_{t}\left(1-\lambda_{t+1}^{w e}\right)}{1+r_{t+1}^{w e}\left(1-\lambda_{t+1}^{w e}\right)}\right\}
$$

Given the dynamic written above, with relation [28], we have:

$$
k_{t+1}^{w e}=R i C V i_{t}^{w e}\left\{\frac{\frac{\left[1+\left(F_{K}\left(k_{t+1}^{w e}, e_{t+1}\right)-\delta\right)\left(1-\lambda_{t+1}^{w e}\right)\right]^{\sigma-1}}{[\vartheta(1-\varphi)]^{\sigma}}}{1-\frac{\left[1+\left(F_{K}\left(k_{t+1}^{w e}, e_{t+1}\right)-\delta\right)\left(1-\lambda_{t+1}^{w e}\right)\right]^{\sigma-1}}{[\vartheta(1-\varphi)]^{\sigma}}}\right\}
$$

\section{Some Analyses in a Steady State}

\subsection{The Dynamic Equilibrium}

Looking again at capital accumulation in the economy, it is possible to express it as a function of the variables and parameters.

If $\chi_{t}^{\text {we }}$ is the total savings of young generations:

$$
\chi_{t}^{w e}=s_{t}^{w e}-\left[q\left(1-\xi_{t}\right)-p_{t}\right] E_{t}=\chi\left(w_{t}, r_{t+1}, E_{t}\right)
$$

From equations [30] and [44] the capital dynamic is established by:

$$
K_{t+1}^{w e}=\chi_{t}^{w e}+\left[\left(1-\xi_{t}\right) F_{E}\left(k_{t}^{w e}, e_{t}\right)-p_{t}\right] E_{t}
$$

All in a steady state:

$$
\begin{array}{r}
K^{w e}=\chi^{w e}\left(F_{L}(k, e), F_{k}(k, e), E\right)+\left[(1-\xi) F_{E}(k, e)-p\right] E \\
H=\frac{\phi \psi}{\vartheta}\left(c^{1}+\Gamma c^{2}\right)+\frac{\mu}{\vartheta} E
\end{array}
$$

- a general form which was roughly characterized by Diamond's ${ }^{14}$ steady state, allowing a level of capital to be the solution to the above equation.

\subsection{About the Nature of the Steady State}

We can establish the relationship:

$$
\left\{1-\left[(1-\xi) F_{E}(k, e)-p\right] \frac{E}{K^{w e}}\right\}=\frac{\chi^{w e}\left(F_{L}(k, e), F_{k}(k, e), E\right)}{K^{w e}}
$$

Galor et al. (1989) (see De La Croix et al. (2002), Jouvet et al. (2002) or Jouvet et al. (2006)) have established as a sufficient condition within the framework of an overlapping generations model that there is 'an interior steady state or solution' if:

$$
\operatorname{Lim}_{K^{w e} \rightarrow 0} \frac{\chi^{w e}}{K^{w e}}>1
$$

\section{Checking:}

From relation[18], we have:

$$
\left\{\begin{array}{l}
\left\{1-\left[(1-\xi) F_{E}(k, e)-p\right] \frac{E}{K^{w e}}\right\}=\frac{\chi^{w e}\left(F_{L}(k, e), F_{k}(k, e), E\right)}{K^{w e}} \\
\text { Si } K \rightarrow 0,-\frac{e}{K} \rightarrow-\infty\left[(1-\xi) F_{E}(k, e)-p\right] \frac{E}{K^{w e}} \rightarrow 0
\end{array}\right.
$$

As well as:

$$
\operatorname{Lim}_{K^{w e} \rightarrow 0} \frac{\chi^{w e}}{K^{w e}}=1
$$

This result leads to the conclusion that the assumption concerning the initial allocation of tradable emission permits is unchecked in the case of Galor et al. (1989) within the framework of overlapping generations models.

\subsection{Stability or Instability of the Stationary State}

We have before us a case of a 3-factor model, with two stock-variables. Looking again at equation [54] and after 
differential calculus, we obtain the dynamic of capital at the steady state equilibrium:

$$
\frac{\partial K^{w e}}{\partial E}=\frac{\chi_{1} F_{L E}+\chi_{2} F_{K E}+\chi_{3}+\chi_{4}\left[\left(1-\xi_{t}\right) E F_{E E}+F_{E}\right]-\chi_{5} p}{1-\chi_{1} f_{L K}+\chi_{2} f_{K K}+\chi_{4} E f_{E K}}
$$

From this result, the dynamic equilibrium is stable if:

$$
1-\chi_{1} f_{L K}+\chi_{2} f_{K K}+\chi_{4} E f_{E K}>0
$$

Since:

$\chi_{1} F_{L E}+\chi_{2} F_{K E}+\chi_{3}+\chi_{4}\left[\left(1-\xi_{t}\right) E F_{E E}+F_{E}\right]-\chi_{5} p>0$

Moreover, instead of analyzing the sign of relation[19], we can conclude based on the nature of the equilibrium from relation [20] that we have a corner solution. It could be interesting to analyze the stability conditions with our results. This technical aspect could be the aim of another futher theoretical analysis based on this work.

\section{Conclusion}

In the framework of OLG, we have built a two-part theoretical model. In the first part, there is no environmental policy objective in the presence of pollution. In the second part, under temporal flexibility assumption, a pollution permit system is introduced and considered a financial asset.

Futhermore, this system is coupled with a green fiscal policy which is applied on the sale of environmental assets to firms. We show that the budget surplus compared with the BAU situation could be used for environmental maintenance. It also could be considered a budget for funding international solidarity measures or to generally avoid ecological debt. We also highlight that environmental maintenance operations can generate long-term positive effects which we qualified as 'intergenerational welfare.' To our knowledge, this is the first time that the debate about ecological debt has been introduced in the framework of an overlapping generations model.

We could also consider that the income coming from the sale of pollution permits would increase consumption with respect to well-known global income distribution. However, we have targeted savings, which allows for the deduction of those parts of income that are not consumed to be saved, thus emphasizing capital accumulation and/or investment.

As excess savings depend on tax levels applied on incomes based on financial assets, it is also important to discuss the tax regime. The Public Authority needs to levy sufficient taxes for environmental maintenance and for the participation of Supranational Committees. Otherwise, as taxes are lowered, so will the Environmental operations fund, leading to an environmental debt for future generations if the Public Authority creates a deficit to cover these environmental expenses.

Moreover, if the tax level is high, this could affect young households' incentive. Therefore, we assume that the tax level is fixed at an optimal level that allows the system to operate under the assumptions in the model.

To conclude, we studied the theoretical effects of Pollution Permits in a steady state. We then characterized the equilibrium, as we have a corner solution which characterizes our assumption about the allocation rule defined in this framework. It would, however, be interesting to study as well other tradable emission permits and their initial allocation following those studied by Jouvet et al. (2002). ㅁ.

\section{References}

Beder, S., (1996), 'The Nature of Sustainable Development,' 2nd edition, Scribe, Newham, Vic.

Bréchet, T., Lambrecht, S., Prieur, F., (2005), 'Régulation optimale des droits de propriété sur l'environnement,' Climneg Working Paper.

Beltrati, A. (1996) 'Emissions Permits in a Dynamic Model with Overlapping Generations,' Nota Di Lavoro 4395.

Brooke, Kendrick \& Meeraus (1992) 'GAMS user's guide' (www.gams.com).

Diamond P.A (1965), 'National Debt in a Neoclassical Growth Model,' American Economic Review, vol 30, pp. 657-740.

De la Croix D., Michel Ph. (1999), 'The overlapping Generations Approach to capital

Accumulation,' D.T, GREQAM.

Directive Européenne 2003/87/CE.

Fullerton, D., Heutel, G., (2007), 'The general equilibrium incidence of environmental taxes,' Journal of Public Economics (91), pp. 571-591.

Galor O., Ryder H.E. (1989), 'Existence, Uniqueness, and Stability of equilibrium in an Overlapping Generations Model with productive capital,' Journal of Economic Theory, vol. 49, pp. 360-375.

Gerlagh, R., van der Zwaan, B.C.C, (2000), 'The effects of ageing and an environmental trust fund in an overlapping generations model on carbon emission reductions,' Ecological Economics (36), pp. 311-326.

Gonalez, M. (2005), 'Impact of Climate Policy on the Basque Economy,' FEEM, Nota di lavoro 113.2005.

Grimaud, A. (1999), 'Pollution Permits and Sustainable Growth in a Schumpeterian Model,' Journal of Environmental Economic and Management 38, 249-266. 
John, A., Pecchenino, R. (1994), 'An overlapping generations model of growth and the environment,' The Economic Journal, vol. 104, pp. $1393-$ 1410.

John, A., Pecchenino, R., Schimmelpfennig, D Schreft S. (1995), 'Shortlived agents and long-lived environment,' Journal of Public Economics, vol. 58, pp. 127-141.

Jouvet, P-A., Prieur, F. (2006), 'Permis de pollution et contraintes politiques dans un modèle à générations imbriquées,' Document de travail - Economix.

Jouvet, P-A., Michel, P., Vidal, J-P. (2002), 'Effets des permis de pollution sur l'accumulation du capital dans le cadre des modèles à générations imbriquées,' Economie et Prévision $n^{\circ} 156$, pp. 63-72, La Documentation française.

Labandeira X., Labeaga J., Rodríguez, M. (2004a), 'Green tax reforms in Spain,' European Environment, (14), pp. 190-299.

Labandeira, X., Labeiga, J., Rodriguez, M. (2004b), 'New analytical approach integrating micro and macro-economic models to simulate energy policies,' Working Paper, Univ. of Vigo.

Lambrecht, S., [2005b], 'Maintaining environmental quality for overlapping generations,' version révisée du Climneg Working Paper $n^{\circ} 59,2004$.

Musu I., Lines, M. (1995), 'Endogenous Growth and Environmental Preservation' in Boreo G., Silberston A. (eds). Envrionmental economics: Proceedings of a conference held by the Confederation of European Economic Associations at Oxford, 1993. NY: St. Martin's Press, London : MacMillan Press, pp. 273-286.

Obstfeld, M., Kenneth, R. (1997), 'Foundations of international macroeconomics,' The MIT Press, 2ème edition, Cambridge.

Ono, T. (1996), 'Optimal tax schemes and the environmental externality,' Economics Letters, vol. 53, pp. 283-289.

Ono, T. (2002), 'The effects of Emission Permits on Growth and the Environment', Environmental \& Resource Economics, European Association of Environmental and Resource Economists, vol. 21(1), pages 75-87, January.

Protocole de Kyoto (1997).

Schubert, K. (2000), 'Macroéconomie, Comportements et croissance,' Vuibert $2^{\mathrm{ème}}$ édition.

Truman F. Bewley. (2007) 'General Equilibrium, Overlapping Generations Models and Optimal Growth Theory,' Harvard University Press, Cambridge 